\title{
The analysis of the methods of research the influence of nonuniform local stress on a crack resistance of protective coating
}

\author{
Ludmila Frishter ${ }^{1, *}$ \\ ${ }^{1}$ Moscow State University of Civil Engineering, Yaroslavskoye shosse, 26, Moscow, 129337, \\ Russian Federation
}

\begin{abstract}
The article deals with a complex analysis methods for studying the influence of local stress on the crack resistance of coatings of buildings and constructions. The consider the computational-experimental methods of research areas of local concentration of stresses structures due to the border shape (angular cuts) under the influence of internally discontinuous deformations entering into a source of geometric stress concentration. Based on data obtained with the analysis of complex naturalistically - factbased and computational-experimental methods to reliably estimate crack resistance of protective coatings of buildings and constructions.
\end{abstract}

\section{Introduction}

The main type of fracture coating surfaces of buildings and constructions is their cracking. Analysis of crack resistance of coatings in the construction and operation of buildings can be reduced to the problem of determining the local stress-strain state caused by the geometrical inhomogeneity surfaces of coatings and their foundations.

Providing the long-term performance properties of coatings of buildings and constructions that perform protective, special, decorative functions, places greater demands on the quality of materials, their performance properties.

During the construction of buildings, the amount of finishing work on labor costs is at least $30 \%$ of all labor costs. Maintaining in operating condition of buildings and constructions during the operation determines the application of coating compositions in large quantities, which leads to a rise in the cost of operation. Competition in the market of finishing materials determines the increased demands on the quality of finishing materials and their performance properties.

Create high-quality coatings of buildings and constructions determines the relevance of the analysis of the methods evaluation and predicting of crack resistance of coating, it helps to increase their service life.

The purpose of the work is to analyze the methods for evaluating the crack resistance of the coating buildings and application of theoretical-experimental method for assessing the local stress-strain state caused by the geometric heterogeneity.

\footnotetext{
* Corresponding author: frishter@mail.ru
} 


\section{Analysis of methods to solve the problem}

The quality of protection-decorative coatings of exterior walls of buildings in accordance with the normative literature is produced by the full-scale fact-based parameters of generalized evaluations of protection-decorative properties [1-10].

In the works Loganina V.I., Makarova L.V., Makridin N.I. and Orentlikher L.P. analyzes the results of many years of inspections condition of painted surfaces of building facades on the example of Penza buildings, which allowed to classify basic types of defects that affect the quality of protection-decorative coatings.

In the works of Makarova L.V. [5] shows the results of inspections of residential buildings according to GOST 9.039-74 "Corrosion aggressiveness of the environment", located in the climatic region IV (moderately cold). Inspection reveals a painted surface buildings [5] the following defects: cracking, spalling, weathering, retention of dirt, wet spots, color variation.

According to the data defect such as cracks of coating along the vertical joint panels, the most common and account for $23-66 \%$ of the total number of defects in the coating depending on the type and service life. After five years of operation, a number of major defects include cracks of coating along the vertical joint over the face of the building.

Currently there are no approaches or methods for qualitative and quantitative evaluation of crack resistance of materials [9]. Among the used evaluation methods crack resistance of coatings surfaces, highlighted the following main groups [5]:

- indirect methods of evaluation of the physicomechanical properties;

- methods of direct evaluation crack resistance;

- methods of evaluation, based on the modeling of the structure of the material;

- methods of evaluation of the energy parameters of deformation and destruction of material;

theoretical-experimental methods for solving the problem of stress - strained state (SSS) in the field of local stress concentration due to the form of the border, for example, an angular cut.

Indirect methods estimate of crack resistance by coefficient considering physicalmechanical properties of coatings, or combinations thereof: elastic modulus, the limiting stretchability, the ultimate extensibility, shrinkage deformation and other properties. Such an approach was proposed by Orentlikher L.P., Novikova I.P., Stolnikova V.V., Silaenkovym E.S., Sheykina A.E. and others.

Methods of direct evaluation of crack resistance based on visual inspections of cracks. The most common of these methods - the method rings, standardized in France and the United States. Its essence is to crimp the sensor, cement system the during shrinkage. This takes into account not only the effect of shrinkage, but also creep, the limiting stretchability, elastic modulus, and other factors. The criterion for the crack resistance is a time of occurrence of the first crack at a reduction. The method is simple, but gives only a qualitative assessment of the crack resistance. Developed by authors such as Popov N.A., Orent-Licher L.P., Lhermitte R., Ruse G.M., Skramtaev B.G. and other.

The method based on energy approach, standardized in Russia (GOST 29167-91 "Concretes. Methods for determination of the crack resistance properties (crack toughness) under static loading"). In a computerized facility made automatically recording diagrams of stress-strain and destruction, and calculation of quantitative parameters the crack resistance. Specific power defined per unit cross-sectional area of the sample.

Widespread in the field of fracture mechanics received acoustic emission method based on excitation, recording and subsequent analysis of the acoustic emission signals received in the form of stress waves by an appropriate converter [2,3]. 
The acoustic emission method makes it possible quantitatively and qualitatively assess the structural changes, plastic deformation, kinetics of defects at various kinds of mechanical action on the material. Given that the main type of the destruction of protectiondecorative coating is cracking, the use of acoustic emission method in predicting the crack resistance buildings coatings is one of the ways to solve the actual problem - increase their service life.

With regard to protection-decorative coatings, the problem of crack resistance almost not developed and solved [9].

Currently, evaluation of crack resistance of protection-decorative coatings produced by the method of V. Shneyderovoy [10]. The method consists in modeling stretching reinforced concrete element to cracking under the coating. Coating condition over the crack width shall be measured evaluated for its continuity at 20-30- fold magnification using an optical device. An indicator of the crack resistance are taking the width of the crack opening, when it was observed the formation of the first defect in the coating over crack.

In a phenomenological study covers defects [5] identified the most common and accepted as a characteristic species of cracking of coatings (10 species) and considered the cracks, depending on their density distribution (4 species). Makarova L.V. studied the use of coatings on their properties depending on the composition of the coating [5], the estimation of the adhesive strength of coatings, identified regularities in coating cracking in the aging process.

Based on the analysis of results obtained using the proposed technique of evaluating the crack resistance coatings [5] and the method of acoustic emission observed different character of change stress intensity factor in the coatings, depending on the type of coating, the length and nature of aging, as well as the proposed materials science path increasing the crack resistance protection-decorative coatings.

Makarova L.V. proposed methodology for assessing the crack resistance of protectiondecorative coatings make it possible to develop a composition putty intended for leveling concrete and plaster surfaces, which includes: the sludge from the neutralization of a polishing mixture of glass industry, sodium hydroxide, hydrated lime, CMC glue, liquor liquid glass, and determine the basic physical and mechanical properties developed fillings.

Carried out analysis of experimental methods to assess the strength and durability of the coatings, based on natural data, leads to the need to develop theoretical and experimental methods for the determination of the stress-strain state of the coating in a crack zone taking into account the shrinkage and periodic changes in temperature, the strength characteristics.

Research of SSS structures: coating-base in the area of the local concentration of stress caused by the form (angular cuts), the need for further investigation of cracking process.

\section{Theoretical foundations of the method}

Consider the computational-experimental methods for studying the local concentration zones structures caused by the form boundaries (angular cuts) under the action of the forced rupture strain emerging in the source geometric stress concentration [11,12].

According to theoretical analysis [11,12] solution to the problem of elasticity theory in the neighborhood of a singular point of a plane domain of the boundary, which includes a finite discontinuity (jump) of forced strains represented in the form:

$$
\eta=\eta^{c}+\eta^{n}
$$

where $\eta^{c}$ - "proper" the solution of the homogeneous boundary value problem in a neighborhood of a singular point of the boundary area, characterizing feature of the solution; 
$\eta^{(n)}-\mathrm{SSS}$, due to the action of the given loads, depending on the geometrical parameters "degree of proximity" to the singular point. The representation (1) is valid in the spatial case for points on the special boundary line.

According to the theoretical VAT representation in the form of (1) in the neighborhood of a singular point of a plane domain boundary there are two self- balanced stress state. The first - the radial self- balanced stress state obtained as a solution to a flat homogeneous boundary value problem in a neighborhood of a singular point of the boundary region, passing in a singular state of stress at the approach to the singular point inside the boundary. Another remaining part, self-balanced plane stress in the top of the corner cutout border corresponds to the stresses caused by the action of given loads or general stress field.

An experimental solution by the method of photoelasticity in the neighborhood of a singular point of a plane domain of the boundary is considered a composite on flat model, in one of the areas where $\left(\Omega_{2}\right)$ to create a free temperature deformation $\alpha T \delta_{i j}$, while the other region $\left(\Omega_{1}\right)$ is free from stress. The line of contact areas out in an singular boundary point - the top corner cutout border plate with different angles of opening.

In the field of non-singular solutions of the homogeneous plane elastic problem possible derive estimates using that, you can extrapolate the data on the cross section, located close to an irregular boundary point, in view of the experimental data and practical measurement accuracy of the method photoelasticity.

According to theoretical-experimental analysis of the state of stress in the neighborhood of a singular point of a plane domain of the boundary, which comes to a jump of forced deformation, proposes the following formula for the extrapolation of the experimental data:

$$
m_{i+1}=\left(\frac{r_{i}}{r_{i+1}}\right)^{1-\lambda_{0}} m_{i},
$$

where $m_{i}$ stripes orders according to an experiment in design section $r_{i}$ in the neighborhood of a nonsingular solution of the homogeneous boundary value problem, $m_{i+1}$ stripes orders in cross-section of smaller radius $r_{i+1}<r_{i}$, located in an area with unreadable or "bad" to read a picture izohrom model, $\lambda_{0}=\min \operatorname{Re} \lambda-$ the minimum value of the real part of the complex roots of the characteristic equation of the homogeneous boundary value problem for the wedge model, determined settlement [12].

In the above sections are practically identical diagrams orders stripes constructed by the relation (2) and the experimental data directly on the picture stripes of model. Match diagrams stripes orders allows you to apply the formula (2) to extrapolate the experimental data [13].

\section{Discussion}

The proposed computational-experimental method allows you to obtain and analyze SSS of structures in the area of stress concentration due to the constructive form of boundaries and discontinuous forced deformations. Possible to consider formation of cracks, in particular, angled in the coating and its base during the crack growth as well as crack formation in the region of the end coupling of the coating and base. 


\section{Conclusions}

On the basis of the data obtained with the use of the proposed complex natural-fact-based and computational-experimental methods to reliably estimate the crack resistance protective coatings and bases, as well as the development of recommendations and ways to improve the crack resistance and durability of protection-decorative coating of construction components and structures.

\section{References}

1. I.Z. Aronov, Nadezhnost' i kontrol' kachestva 8, 15-18 (1995)

2. V.A. Greshnikov, Akusticheskaya emissiya, Izdatel'stvo standartov (1976)

3. Y.G. Kudryavtseva, Izvestiya vuzov. Stroitel'stvo 3, 72-76 (1982)

4. V.I. Loganina, Stoykost' zashchitno-dekorativnykh pokrytiy naruzhnykh sten zdaniy, Izdatel'stvo Assotsiatsii stroitel'nykh vuzov (1999)

5. V.I. Loganina, L.V. Makarova, N.I. Makridin, Prognozirovanie treshchinostoikosti dekorativnykh pokritiy naruzhnykh sten zdaniy. Monografiya, Privolzhskiy dom znaniy (2004)

6. L.P. Orentlikher, Izvestiya vuzov. Stroitel'stvo i arkhitektura 8, 63-64 (1988)

7. L.P. Orentlikher, Stroitel'nye materialy 10, 27-29 (1986)

8. L.P. Orentlikher, Izvestiya vuzov. Stroitel'stvo 6, 128-130 (2001)

9. D.V. Oreshkin, Sed'mye akademicheskie chteniya RAASN, 396-402 (2011)

10. L.Y. Frishter, Academia. Arkhitektura i stroitel'stvo. Rossiyskaya akademiya arkhitektury i stroitel'nykh nauk 4, 94-97 (2008)

11. L.Y. Frishter, Vestnik MGSU 1, 165-168 (2008)

12. L.Y. Frishter, Vestnik MGSU 1, 272-276 (2008)

13. V.V. Shneyderova, Antikorroziynye lakokrasochnye pokrytiya, Stroyizdat (1982) 